Pesq. Vet. Bras. 30(12):1003-1009, dezembro 2010

\title{
Nematóides resistentes a alguns anti-helmínticos em rebanhos caprinos no Cariri Paraibano'
}

\author{
Wagner C. Lima ${ }^{*}$, Ana C.R. Athayde ${ }^{3}$, Geovergue R. Medeiros ${ }^{4}$, Dayanne \\ A.S.D. Lima², Jucileide B. Borburema ${ }^{2}$, Edson M. Santos ${ }^{5}$, Vinícius L.R. \\ Vilela ${ }^{6}$ e Sérgio S. Azevedo ${ }^{3}$
}

\begin{abstract}
Lima W.C., Athayde A.C.R., Medeiros G.R., Lima D.A.S.D., Borburema J.B., Santos E.M., Vilela V.L.R. \& Azevedo S.S. 2010. [Nematode resistant to some anthelmintics in dairy goats in Cariri Paraibano, Brazil.] Nematóides resistentes a alguns anti-helmínticos em rebanhos caprinos no Cariri Paraibano. Pesquisa Veterinária Brasileira 30(12):1003-1009. Curso de Pós-Graduação em Medicina Veterinária, Centro de Saúde e Tecnologia Rural, Campus de Patos da Universidade Federal de Campina Grande, Patos, PB 58700-000, Brazil. E-mail: atsocamil@yahoo.com.br

The aim of this paper was to evaluate the resistance of nematodes to some anthelmintics in dairy goats in Cariri Paraibano, Brazil. A total of 144 female goats, over 8 months of age, were used in the dry season and 120 ones during the rainy season, divided into four groups: Group I untreated, Group II treated with albendazole 10\%, Group III treated with ivermectin $1 \%$, and Group IV treated with levamisole phosphate $18.8 \%$, at doses recommended by the manufacturer. To evaluate the resistance, the reduction in egg count per gram of feces and the cultivation of larval helminths. The fecal samples were collected on the day of treatment and, after 7, 14 and 21 days of treatment. In the group treated with albendazole, 61\%, 11\% and $24 \%$ of efficiency was observed in the dry period, and $55 \%, 14 \%$ and $12 \%$ in the rainy season, at 7,14 , and 21 days respectively. In the group treated with ivermectin, efficacy was $14 \%, 70 \%$ and $66 \%$ for the dry period, and $76 \%, 34 \%$ and $71 \%$ for the rainy season, at 7,14 and 21 days respectively. The group treated with phosphate Levamisole showed efficacy rates of $89 \%, 79 \%$ and $73 \%$ in the dry period, and $76 \%, 69 \%$ and $67 \%$ in the rainy season, at 7, 14 and 21 days. The results indicate that the gastrointestinal nematodes of some dairy goats in Cariri Paraibano are not sensitive to the active Albendazole, Levamisole and Ivermectin. During the study, presence of specimens of the genera Haemonchus, Trichostrongylus, Oesophagostomum and Strongyloides was identified.
\end{abstract}

INDEX TERMS: Albendazole, ivermectin, levamisole, gastrointestinal nematodes.

\footnotetext{
${ }^{1}$ Recebido em 9 de março de 2010.

Aceito para publicação em 24 de julho de 2010.

2 Programa de Mestrado em Medicina Veterinária, Centro de Saúde e Tecnologia Rural (CSTR), Universidade Federal de Campina Grande (UFCG), Campus de Patos, 58700-000, Patos, PB Brasil. *Autor para correspondência: atsocamil@yahoo.com.br

3 Unidade Acadêmica de Medicina Veterinária, CSTR, UFCG, Patos, PB 58700-000.

${ }^{4}$ Instituto Nacional do Semiárido, Av. Floriano Peixoto $715,2^{\circ}$ andar, Centro, Campina Grande, Paraíba, PB 58400-165.

${ }^{5}$ Departamento de Zootecnia, Centro de Ciências Agrárias, Universidade Federal da Paraíba (UFPB), Campus II, Areia, PB 58397-000.

${ }^{6}$ Curso de Medicina Veterinária, CSTR, UFCG, Campus de Patos, 58700-000, Patos, PB.
}

RESUMO.- Objetivou-se avaliar a resistência de nematódeos a alguns anti-helmínticos em rebanhos caprinos no Cariri Paraibano. Foram utilizados 144 animais no período seco e 120 animais no período chuvoso, fêmeas com idade acima de oito meses de vida e lactantes, distribuídos em 4 grupos: Grupo I não tratado, Grupo II tratado com albendazole a 10\%, Grupo III tratado com ivermectina a $1 \%$ e Grupo IV tratado com fosfato de levamisole a $18,8 \%$, nas doses recomendadas pelos fabricantes. Para avaliar a resistência, aplicou-se o teste de redução na contagem de ovos por grama de fezes (RCOF) e o cultivo de larvas de helmintos. As amostras fecais foram coletadas no dia do tratamento (dia base) e 7, 14 e 21 dias após o tratamento. No grupo tratado com Albendazole, observaram-se eficácias de $61 \%, 11 \%$ e $24 \%$ no período 
seco e de $55 \%, 14 \%$ e $12 \%$ no período chuvoso, aos 7,14 , e 21 dias, respectivamente. No grupo tratado com Ivermectina, a eficácia foi de $14 \%, 70 \%$ e $66 \%$ para o período seco, e de $76 \%, 34 \%$ e $71 \%$ para o período chuvoso, aos 7,14 e 21 dias, respectivamente. O grupo tratado com fosfato de Levamisole apresentou percentuais de eficácia de $89 \%, 79 \%$ e $73 \%$ no período seco e de $76 \%, 69 \%$ e $67 \%$ no período chuvoso, aos 7, 14 e 21 dias, respectivamente. Os resultados obtidos indicam que os nematódeos gastrintestinais de alguns rebanhos caprinos no Cariri Paraibano não são sensíveis aos princípios ativos Albendazole, Levamisole e Ivermectina. Durante o período de estudo foi identificada a presença de parasitas dos gêneros Haemonchus, Trichostrongylus, Oesophagostomum e Strongyloides.

TERMOS DE INDEXAÇÃO: Albendazole, ivermectina, levamisole, nematódeos gastrintestinais.

\section{INTRODUÇÃO}

A caprinocultura é uma atividade econômica que já se encontra em bastante expansão na região Nordeste do Brasil, sendo uma fonte de proteína de origem animal com importante relevância socioeconômica para quem vive dessa atividade. Ela é restringida pelo desenvolvimento de parasitoses gastrintestinais que limitam a produção caprina, responsáveis por elevadas perdas econômicas devido a redução no consumo de alimentos, perda de peso, crescimento retardado, baixa fertilidade, queda na produção de leite e, nos casos de infecções maciças, mortalidade acentuada.

Vários princípios ativos de anti-helmínticos vêm sendo utilizados no tratamento de nematódeos, principalmente os grupos dos benzimidazóis (Albendazole, Fenbendazole e Oxfendazole), das avermectinas (Ivermectina); dos imidazotiazoles (Cloridrato de levamisole) e das salicilanilidas (Closantel sódico) (Borges 2003).

Os escassos conhecimentos sobre os mecanismos de sobrevivência dos parasitos e o decréscimo de investimentos na inovação de moléculas antiparasitárias diminuem as perspectivas de surgimento de novos grupos químicos eficazes no controle das parasitoses (Geary \& Thompson 2003).

Os fatores ambientais têm grande influência sobre a composição e a regulação da população parasitária, principalmente sobre estádios larvares no pasto, inclusive sobre a predominância de uma ou mais espécies em determinadas regiões. Em países de clima tropical a temperatura e a umidade são consideradas os mais importantes fatores responsáveis pelo desenvolvimento de ovos e larvas no ambiente (Valcarcel et al. 1999).

Rodrigues et al (2007), realizando um estudo na mesorregião do Sertão Paraibano para avaliar a sensibilidade de nematóides gastrintestinais de caprinos a compostos antihelmínticos, determinaram que estes parasitas não foram efetivamente sensíveis à ação do albendazole e da ivermectina, mas moderadamente sensíveis ao cloridrato de levamisole.
Este trabalho foi realizado com o objetivo de avaliar a resistência a alguns anti-helmínticos em rebanhos caprinos no Cariri Paraibano.

\section{MATERIAL E MÉTODOS}

Local de realização do experimento e o período de execução. $O$ experimento foi desenvolvido em propriedades localizadas na região de Monteiro, Paraiba, e as análises foram realizadas nos Laboratórios de Doenças Parasitárias dos Animais Domésticos (LDPAD) e Ciências Químicas Biológicas (LCQB) do Centro de Saúde e Tecnologia Rural (CSTR) da Universidade Federal de Campina Grande (UFCG), Campus de Patos. O período de execução do estudo foi de agosto de 2008 a janeiro de 2009 (período seco) e de março a agosto de 2009 (período chuvoso).

Seleção das propriedades. Foram selecionadas 8 propriedades e feito um levantamento sócio-econômico e epidemiológico através de entrevistas e questionários para obtenção de informações e coletas de fezes.

Animais utilizados no experimento. Foram utilizados 144 animais no período seco e 120 animais no período chuvoso, fêmeas, com idade acima de oito meses de vida e lactantes. Os animais foram identificados individualmente por meio de colares e aleatoriamente distribuídos em quatro grupos: Grupo I não tratado, Grupo II tratado com albendazole a $10 \%$, Grupo III tratado com ivermectina a 1\%, e Grupo IV tratado com fosfato de levamisole a $18,8 \%$.

Descrição da posologia empregada nos tratamentos. As doses utilizadas foram as recomendadas pelos fabricantes e pelo LCQB/CSTR/UFCG. Aos animais do Grupo I não foram administrados medicamentos; aos animais do Grupo II foi administrado albendazole na dose de $0,75 \mathrm{~mL} / 20 \mathrm{~kg}$ via oral; aos animais do Grupo III foi administrada ivermectina na dose de $1,0 \mathrm{~mL} / 50 \mathrm{~kg}$ via subcutânea; e aos animais do Grupo IV foi administrado fosfato de levamisole na dose de $1,0 \mathrm{~mL} / 40 \mathrm{~kg}$ via subcutânea.

Amostras fecais foram coletadas diretamente da ampola retal, acondicionadas em sacos plásticos, identificadas e mantidas sob refrigeração até o processamento para determinação do número de ovos por grama de fezes (OPG) e para a obtenção das larvas. As coletas foram feitas no dia do tratamento (dia base), 07, 14 e 21 dias após tratamento.

Exames parasitológicos. Foram realizadas as contagens dos OPGs pela técnica descrita por Gordon \& Whitlock (1939) e a realização do cultivo de larvas de helmintos pela técnica de Roberts \& O'Sullivan (1950). Para a identificação das larvas utilizou-se a chave de Keith (1953).

Teste de redução da contagem de ovos por grama de fezes. As médias aritméticas do número de ovos nas fezes para cada grupo tratado (OPGt), foram calculadas e comparadas com as médias contadas no grupo controle (OPGc). A redução na contagem de ovos nas fezes (RCOF) foi determinada usando a fórmula descrita por Coles et al. (1992):

$$
\text { RCOF }=[1-(\mathrm{OPG} / \mathrm{OPGc})] \times 100
$$

Em que: RCOF = teste de redução da contagem de ovos por grama de fezes;

OPGt = média do número de ovos por grama de fezes do grupo de animais tratados;

OPGc = média do número de ovos por grama de fezes do grupo controle. 
A avaliação da eficácia dos fármacos utilizados baseou-se no Regulamento Técnico da Portaria no 48/1997 do Ministério da Agricultura e do Abastecimento para substâncias químicas dotadas de atividade antiparasitária utilizando-se o seguinte critério: é altamente efetivo quando reduz mais que $98 \%$; efetivo $90-98 \%$; moderadamente efetivo $80-89 \%$; e insuficientemente ativo menos que $80 \%$, não registrável (Ministério da Agricultura e do Abastecimento 1997).

Para resumo dos dados, foi utilizada a média ou mediana como medida de tendência central, e o desvio padrão ou intervalo interquartil como medidas de dispersão dependendo da distribuição dos dados. Para a comparação dos diferentes grupos experimentais, foi utilizado o teste não-paramétrico de Kruskal-Wallis com as comparações múltiplas realizadas com o teste de Dunn (Zar 1999) para variáveis com distribuição não normal. Variáveis com distribuição normal foram comparadas com a ANOVA de um critério de classificação com as comparações múltiplas efetuadas com o teste de Tukey. O nível de significância adotado foi de 0,05.

\section{RESULTADOS E DISCUSSÃO}

Durante o período de janeiro a agosto de 2009, as quantidades de chuvas acumuladas variaram de 30 a $335 \mathrm{~mm}$. Nos meses de abril e maio foram registradas as maiores quantidades de chuvas acumuladas, 245 e $335 \mathrm{~mm}$, respectivamente, superando as quantidades esperadas para os mesmos meses que é de $150 \mathrm{~mm}$ e $65 \mathrm{~mm}$, respectivamente (Instituto Nacional de Meteorologia, 2009) (Fig.1). A temperatura e umidade são importantes fatores que influenciam o desenvolvimento dos estágios de vida livre dos nematóides gastrintestinais (Soulsby 1987). As temperaturas médias anuais no Cariri Paraibano variam entre $25^{\circ} \mathrm{C}$ a $27^{\circ} \mathrm{C}$ (Nascimento \& Alves 2008), sendo, portanto, consideradas eleva-

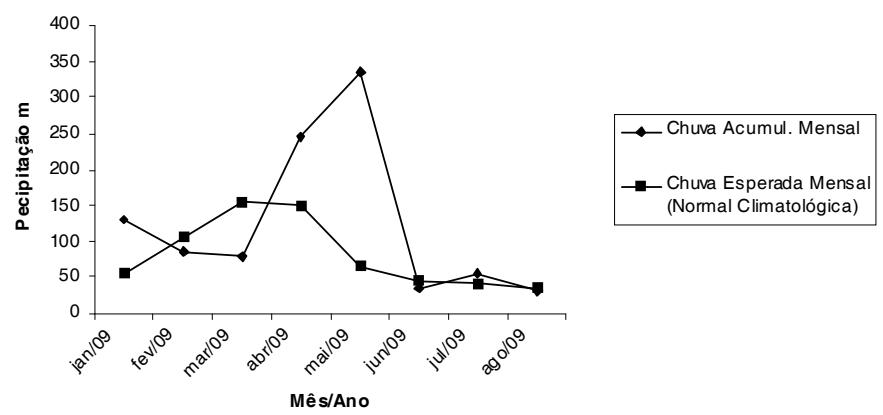

Fig.1. Chuvas mensais e esperadas durante os meses de janeiro a agosto de 2009 na região de Monteiro, Paraíba, Brasil. (Fonte: Instituto Nacional de Meteorologia, 2009) das o que propicia uma maior eclosão de ovos de parasitas, uma vez que temperaturas baixas e altas podem retardar ou acelerar, respectivamente, a eclosão dos ovos destes parasitos (Le Jambre \& Whitlock 1976).

Os dados obtidos na redução da contagem do OPG nos animais tratados se encontram descritos nos Quadros 1 e 2 e o percentual de propriedades nas quais os antihelmínticos foram altamente efetivos, efetivos, moderadamente efetivos e insuficientemente ativos se encontram descritos nos Quadros 3 e 4.

Na época seca, os maiores valores $(P<0,05)$ de OPG no dia sete foram observados no grupo controle, seguido dos grupos tratados com ivermectina, albendazole e levamisole. No dia 14 o maior valor $(P<0,05)$ foi observado no grupo controle, seguido pelo grupo albendazole, ivermectina e levamisole. No dia 21 o maior valor foi observado no grupo controle, seguido de albendazole, ivermectina e levamisole, e esses dois últimos não diferiram entre si.

Para a época chuvosa, os maiores valores $(P<0,05)$ de OPG no dia sete foram observados para o grupo controle e o grupo albendazole que não diferiram entre si $(P>0,05)$, e os menores valores $(P<0,05)$ foram observados para os grupos ivermectina e levamisole que não diferiram entre si ( $P>0,05)$. O mesmo fato foi observado nos dias 14 e 21.

No grupo tratado com albendazole, observaram-se eficácias de $61 \%, 11 \%$ e $24 \%$ no período seco e de $55 \%$, $14 \%$ e $12 \%$ no período chuvoso, aos sete, 14, e 21 dias, respectivamente, caracterizando-se assim como uma droga insuficientemente ativa, ou ainda, não registrável, segundo preconiza o Ministério da Agricultura e do Abastecimento (1997). Resultados semelhantes aos de Pereira et al (2008) no estado do Rio Grande do Norte onde encontraram redução de 2,92\%, 9,63\% e 21,10\% aos sete, 14 e 21 dias pós-tratamento. Resultados que não corroboram com Ahid et al (2007) que encontraram um percentual de $97,89 \%, 71,2 \%$ e $80 \%$ em rebanho caprino no estado de Alagoas e Melo et al (2009) ao estudarem caprinos e ovinos em 25 fazendas na região semiárida do estado do Ceará com eficácia de até $96 \%$ para caprinos ao utilizarem benzimidazóis (oxfendazol). Rodrigues et al (2007) constataram $65 \%, 60,3 \%$ e $75 \%$ de eficiência em caprinos no estado da Paraíba, reforçando ainda mais a presença da resistência frente ao principio ativo albendazole nesse estado. A resistência deve-se talvez pela larga utilização deste, causando aumento ou manutenção da alta freqüência dos alelos da resistência. Além disso, pode haver migrações

Quadro 1. Média da redução do número de ovos por grama de fezes (OPG) de nematódeos gastrintestinais e percentuais médios da eficácia de drogas anti-helmínticas em caprinos na região do Cariri Paraibano em diferentes períodos de observação durante a época seca

\begin{tabular}{lccccccc}
\hline \multirow{2}{*}{$\begin{array}{c}\text { Anti-hel- } \\
\text { míntico }\end{array}$} & OPG (dia0) & OPG (dia7) & Eficácia(\%) & OPG (dia14) & Eficácia (\%) & OPG (dia21) & Eficácia (\%) \\
\cline { 2 - 8 } & 772,22 & $900,00^{\mathrm{a}}$ & - & $425,00^{\mathrm{a}}$ & - & $597,14^{\mathrm{a}}$ & - \\
Controle & 750,00 & $347,22^{\mathrm{C}}$ & $61,0 \%$ & $380,00^{\mathrm{b}}$ & $11,0 \%$ & $451,43^{\mathrm{b}}$ & $24,0 \%$ \\
Albendazole & 552,78 & $769,44^{\mathrm{b}}$ & $14,0 \%$ & $127,78^{\mathrm{C}}$ & $70,0 \%$ & $202,78^{\mathrm{C}}$ & $66,0 \%$ \\
Ivermectina & 688,89 & $102,78^{\mathrm{d}}$ & $89,0 \%$ & $88,89^{\mathrm{d}}$ & $79,0 \%$ & $161,11^{\mathrm{c}}$ & $73,0 \%$ \\
Levamisole & & &
\end{tabular}

Médias seguidas de letras diferentes nas colunas diferem entre $s i(p<0,05)$. 
Quadro 2. Média da redução do número de ovos por grama de fezes (OPG) de nematódeos gastrintestinais e percentuais médios da eficácia de drogas anti-helmínticas em caprinos na região do Cariri Paraibano em diferentes períodos de observação durante a época chuvosa

\begin{tabular}{lccccccc}
\hline \multirow{2}{*}{$\begin{array}{c}\text { Anti-hel- } \\
\text { míntico }\end{array}$} & OPG (dia0) & OPG (dia7) & Eficácia (\%) & OPG (dia14) & Eficácia (\%) & OPG (dia21) & Eficácia (\%) \\
\cline { 2 - 7 } Controle & 963,33 & $1526,67^{\mathrm{a}}$ & - & $1879,31^{\mathrm{a}}$ & - & $1434,48^{\mathrm{a}}$ & - \\
Albendazole & 990,00 & $683,33^{\mathrm{a}}$ & $55,0 \%$ & $1610,00^{\mathrm{a}}$ & $14,0 \%$ & $1260,00^{\mathrm{a}}$ & $12,0 \%$ \\
Ivermectina & 983,33 & $358,62^{\mathrm{b}}$ & $76,0 \%$ & $634,48^{\mathrm{b}}$ & $34,0 \%$ & $413,79^{\mathrm{b}}$ & $71,0 \%$ \\
Levamisole & 1490,00 & $370,00^{\mathrm{b}}$ & $76,0 \%$ & $586,67^{\mathrm{b}}$ & $69,0 \%$ & $466,67^{\mathrm{b}}$ & $67,0 \%$
\end{tabular}

Médias seguidas de letras diferentes nas colunas diferem entre si $(p<0,05)$.

Quadro 3. Percentual de propriedades nas quais os anti-helmínticos albendazole, ivermectina e levamisole foram altamente efetivos, efetivos, moderadamente efetivos e insuficientemente ativos* no controle das helmintoses em caprinos na região do Cariri Paraibano durante a época seca

\begin{tabular}{lccc}
\hline \multirow{2}{*}{ Atividade parasitária } & \multicolumn{3}{c}{ Anti-helmíntico } \\
\cline { 2 - 4 } & Albendazole (\%) & Ivermectina (\%) & Levamisole (\%) \\
\hline Altamente Efetivo (>98\%) & - & 25,0 & 50,0 \\
Efetivo (90-98\%) & 12,5 & 12,5 & - \\
Moderadamente Efetivo(80-89\%) & 12,5 & - & - \\
Insuficientemente Ativo(<80\%) & 75,0 & 62,5 & 50,0 \\
\hline
\end{tabular}

${ }^{*}$ Critérios da Portaria № 48/1997 do Ministério da Agricultura e do Abastecimento

Quadro 4. Percentual de propriedades nas quais os anti-helmínticos albendazole, ivermectina e levamisole foram altamente efetivos, efetivos, moderadamente efetivos e insuficientemente ativos ${ }^{*}$ no controle das helmintoses em caprinos na região do Cariri Paraibano durante a época chuvosa

\begin{tabular}{lcccc}
\hline \multicolumn{1}{c}{ Atividade parasitária } & \multicolumn{3}{c}{ Anti-helmíntico } \\
\cline { 2 - 4 } & Albendazole (\%) & Ivermectina (\%) & Levamisole (\%) \\
\hline Altamente Efetivo (> 98\%) & - & - & 12,5 \\
Efetivo (90-98\%) & - & 37,5 & 12,5 \\
Moderadamente Efetivo (80-89\%) & 12,5 & - & 37,5 \\
Insuficientemente Ativo (<80\%) & 87,5 & 62,5 & 37,5 \\
\hline
\end{tabular}

* Critérios da Portaria no 48/1997 do Ministério da Agricultura e do Abastecimento.

gênicas que introduzem diferentes freqüências provenientes da população de origem e através do fluxo gênico esses genes são incorporados ao conjunto gênico da nova população, provocando a dispersão de alelos de uma população para outra (Silvestre \& Humbert 2002).

No grupo tratado com ivermectina, a eficácia foi de $14 \%$, $70 \%$ e $66 \%$ para o período seco e de $76 \%$, 34\% e $71 \%$ para o período chuvoso, aos sete, 14 e 21 dias, apresentando-se como uma droga insuficientemente ativa, ou ainda, não registrável (Ministério da Agricultura e do Abastecimento 1997). Pereira et al. (2008) no estado do Rio Grande do Norte encontraram redução de $24,9 \%, 12,01 \%$ e $5,96 \%$ aos sete, 14 e 21 dias pós-tratamento. Rodrigues et al. (2007) trabalhando também no estado da Paraíba, obtiveram um percentual de $70,6 \%$ na redução de ovos em caprinos aos 21 dias pós-tratamento. Já Mattos et al. (2003), em Porto Alegre, encontraram aos 14 dias póstratamento um percentual de eficácia de $93,24 \%$ em caprinos e Ahid et al. (2007), em Alagoas, encontraram um per- centual de eficácia de $98,74 \%, 88,3 \%, 87 \%$ aos sete, 14 e 21 dias pós-tratamento na mesma espécie. Determinados genes que codificam proteínas envolvidas no transporte ou metabolismo podem ser a causa da resistência apesar de não desempenharem qualquer papel no mecanismo de ação da droga (Prichard \& Tait 2001). A natureza dos genes e a importância dos mesmos para o estabelecimento da resistência não estão claras, mas esses genes parecem codificar subunidades específicas faringeais e nãofaringeais dos canais cloro com portão glutamato, Pglicoproteínas e outros produtos (Köhler 2001).

O grupo tratado com fosfato de levamisole apresentou percentuais de eficácia de $89 \%, 79 \%$ e $73 \%$, no período seco, $76 \%, 69 \%$ e $67 \%$, no período chuvoso, aos sete, 14 e 21 dias, respectivamente, classificada como uma droga insuficientemente ativa (Ministério da Agricultura e do Abastecimento 1997). Vieira \& Cavalcante (1999) ao estudarem 34 rebanhos caprinos no estado do Ceará, constataram que $25(73,5 \%)$ apresentaram percentual de redução do 
OPG após o tratamento inferior a $90 \%$, sendo sete $(20,6 \%)$ dos rebanhos tratados com cloridrato de levamisole, seis $(17,6 \%)$ dos tratados com oxfendazole e $12(35,3 \%)$ dos tratados com os dois produtos avaliados. Melo et al. (2003) observaram que aos 14 dias pós-tratamento $75 \%$ dos rebanhos caprinos do Ceará apresentou resistência. Já Rodrigues et al. (2007) encontraram eficácia de 96\%, 97,1\% e $91 \%$ aos sete, 14 e 21 dias pós-tratamento em caprinos no Sertão Paraibano. O levamisole é um fármaco com espectro de atividade sobre estágios adultos da maioria dos nematódeos gastrintestinais de ruminantes (Lanusse 1996), apresentando baixa eficácia na eliminação de formas imaturas (Vieira 1989). Esta classe de antiparasitários age como agonista colinérgico na membrana das células da musculatura dos nematódeos. Acredita-se que esta droga e o seu parceiro natural, a acetilcolina, promova a abertura de um canal catiônico, formado por cinco subunidades de proteínas (Molento 2004).

Estudos de contração muscular feitos em cepas susceptíveis e resistentes do nematoda Caenorhabditis elegans, indicaram que existe menor quantidade de receptores para o levamisole em vermes resistentes do que nos susceptíveis. Em cepas mutantes, isto ocorre em uma das subunidades presentes na região transmembrana. Embora ainda seja necessária muita pesquisa para esclarecer este processo, suspeita-se que a resistência do levamisole envolva a perda de sensibilidade contra estes anti-helmínticos na subunidade do receptor colinérgico do parasita (Molento 2004).

Os resultados encontrados no grupo tratado com levamisole podem ser também reflexo do uso indiscriminado desse composto a partir dos resultados obtidos por Rodrigues et al. (2007), sem que houvesse a troca de princípio ativo tecnicamente recomendado.

As diferenças constatadas pelos autores nos percentuais de eficácia, provavelmente sejam decorrentes das diferentes pressões de uso destes princípios ativo em cada região estudada. Buzzulini et al. (2007) ao avaliarem a efi- cácia anti-helmíntica da associação albendazole, levamisole e ivermectina, encontraram $99,5 \%$ de eficácia em ovinos naturalmente infectados por nematódeos gastrintestinais em São Paulo.

Ahmed et al. (2005) compararam a eficácia das formulações albendazole, levamisole e ivermectina em ovinos naturalmente infectados e obtiveram índices de $84,2 \%$, $77,6 \%$ e $40 \%$, respectivamente. Estes resultados indicam a resistência das populações parasitárias aos diferentes grupos químicos utilizados, incluindo as lactonas macrocíclicas, um dos mais modernos e eficazes antiparasitários existentes.

Durante os períodos de estudo foram identificadas as presenças de parasitas dos gêneros Haemonchus, Trichostrongylus, Oesophagostomum e Strongyloides (Quadros 5 e 6). Observa-se que o gênero Haemonchus esteve presente em maior porcentagem em todos os grupos tratados neste estudo, independente da época. Resultados semeIhantes foram encontrados por Rodrigues et al. (2007) no Sertão Paraibano, onde encontraram o gênero Haemonchus, seguido de Bunostomum, Trichostrongylus e Oesophagostomum mesmo após os tratamentos. Já Pereira et al. (2008) encontraram o gênero Haemonchus com a segunda maior porcentagem nos grupos controle e albendazole, e como o único encontrado no grupo da ivermectina. Provavelmente, esse nematódeo desenvolve resistência mais rapidamente devido ao seu alto potencial biótico (Echevarria \& Trindade 1989), grande variabilidade genética e por albergar o alelo que causa a diminuição da susceptibilidade a uma droga (Blackhall et al. 1998).

Nos caprinos tratados com o albendazole observou-se a presença dos gêneros Haemonchus, Trichostrongylus, Oesophagostomum e Strongyloides, resultados também encontrados por Pereira et al. (2008) no estado do Rio Grande do Norte com caprinos, mas que não se assemelham ao de Rodrigues et al. (2007) que encontraram apenas Haemonchus em $100 \%$ nos caprinos estudados no estado da Paraíba.

Quadro 5. Número de larvas de helmintos observadas por intervalo de sete dias, em fezes de caprinos na região do Cariri Paraibano após tratamento anti-helmíntico durante a época seca

\begin{tabular}{|c|c|c|c|c|c|c|c|c|c|c|c|c|c|c|c|c|}
\hline \multirow[t]{2}{*}{ Gêneros } & \multicolumn{4}{|c|}{ Controle $(\%)$} & \multicolumn{4}{|c|}{ Albendazole (\%) } & \multicolumn{4}{|c|}{ Ivermectina (\%) } & \multicolumn{4}{|c|}{ Levamisole (\%) } \\
\hline & 0 & 07 & 14 & 21 & 0 & 07 & 14 & 21 & 0 & 07 & 14 & 21 & 0 & 07 & 14 & 21 \\
\hline & 75 & 77 & 75 & 75 & 7 & 7 & 80 & 81 & 75 & 5 & 79 & 78 & 80 & 78 & 79 & 80 \\
\hline Trich & 15 & 16 & 13 & 15 & 15 & 16 & 14 & 16 & 17 & 15 & 15 & 16 & 17 & 17 & 15 & 13 \\
\hline Oesopha & 9 & 7 & 10 & 8 & 6 & 6 & 5 & 1 & 7 & 9 & 5 & 6 & 1 & 5 & 6 & 6 \\
\hline Strongyloides & 1 & 0 & 2 & 2 & 2 & 0 & 1 & 2 & 1 & 1 & 1 & 0 & 2 & 0 & 0 & 1 \\
\hline
\end{tabular}

Quadro 6. Número de larvas de helmintos observadas por intervalo de sete dias, em fezes de caprinos na região do Cariri Paraibano após tratamento anti-helmíntico durante a época chuvosa

\begin{tabular}{|c|c|c|c|c|c|c|c|c|c|c|c|c|c|c|c|c|}
\hline \multirow[t]{2}{*}{ Gêneros } & \multicolumn{4}{|c|}{ Controle (\%) } & \multicolumn{4}{|c|}{ Albendazole (\%) } & \multicolumn{4}{|c|}{ Ivermectina (\%) } & \multicolumn{4}{|c|}{ Levamisole (\%) } \\
\hline & 0 & 07 & 14 & 21 & 0 & 07 & 14 & 21 & 0 & 07 & 14 & 21 & 0 & 07 & 14 & 21 \\
\hline Haem & 79 & 80 & 83 & 7 & 94 & 8 & 78 & 94 & 73 & 76 & 87 & 70 & 78 & 96 & 90 & 82 \\
\hline Trichostrongylus & 12 & 16 & 7 & 13 & 3 & 9 & 14 & 5 & 23 & 15 & 6 & 22 & 12 & 4 & 10 & 10 \\
\hline Oesophagostomum & 2 & 1 & 6 & 13 & 0 & 4 & 4 & 1 & 4 & 9 & 6 & 4 & 4 & 0 & 0 & 7 \\
\hline Strongyloides & 7 & 3 & 4 & 0 & 3 & 6 & 4 & 0 & 0 & 0 & 1 & 4 & 6 & 0 & 0 & 1 \\
\hline
\end{tabular}


Os animais que foram tratados com a ivermectina apresentaram larvas do gênero Haemonchus, Trichostrongylus, Oesophagostomum e Strongyloides. Pereira et al. (2008) encontraram apenas Haemonchus em 100\% dos caprinos estudados. Rodrigues et al. (2007) na Paraíba encontraram apenas Haemonchus e Bunostomum aos 21 dias após tratamento.

Os parasitos presentes em animais tratados com levamisole apresentaram larvas do gênero Haemonchus, Trichostrongylus, Oesophagostomum e Strongyloides. Pereira et al. (2008) encontraram Haemonchus, Trichostrongylus e Oesophagostomum. Buzzulini et al. (2007), testando a associação albendazole, levamisole e ivermectina, conseguiram reduzir em $93,2 \%$ de Haemonchus contortus, 99,9\% de Trichostrongylus colubriformise 100\% de Cooperia , Strongyloides, Oesophagostomum e Trichuris, em ovinos na região de Jaboticabal, São Paulo.

De acordo com os resultados obtidos através dos questionários, observou-se que dentre as 8 propriedades estudadas, em 6 (75\%) delas a vermifugação dos animais é realizada semestralmente e que, entre os princípios ativos mais utilizados, destacou-se a ivermectina representando $87,5 \%$ (7) do total de propriedades. Observou-se ainda que em apenas $5(62,5 \%)$ destas propriedades a troca de princípios ativos destes fármacos é realizada com a periodicidade de 3 em 3 meses (1), 6 em 6 meses (2) e a cada 12 meses (2).

É provável que o aparecimento da resistência tenha decorrido do uso incorreto dos medicamentos, já que se recomenda vermifugações a cada 3 meses ou de acordo com resultados de exames de OPG realizados nos animais. Outro fator importante que pode ter colaborado para o rápido desenvolvimento da resistência, foi a rápida rotação dos produtos e a utilização do mesmo principio ativo, pois, segundo Molento (2004), a rotação rápida de bases químicas acelera o processo da resistência e em caprinos é recomendado o uso de, no mínimo, 1 ano para então ser realizada a troca.

Diante dos resultados obtidos, observou-se o grave problema por que passa a cadeia produtiva da caprinocultura, tanto pelo uso indiscriminado de anti-helmínticos, como pelo próprio aparecimento de resistências. Esses resultados apresentam conseqüências como aumento dos custos de produção, queda na produção animal e o mais grave, a falta de um produto químico para o controle dos nematódeos gastrintestinais.

\section{CONCLUSÕES}

Os resultados obtidos indicam que os nematódeos gastrintestinais de alguns rebanhos caprinos no Cariri Paraibano não são sensíveis aos princípios ativos albendazole, levamisole e ivermectina.

No gênero Haemonchus estão os parasitas menos sensíveis a todos os princípios ativos testados.

Agradecimentos.- Ao Instituto Nacional do Semiárido pelo total apoio, incentivo e compreensão oferecido durante a realização deste trabaIho; ao Conselho Nacional de Desenvolvimento Científico e Tecnológi- co pelo apoio financeiro; e a Associação dos Ovinocaprinocultores do Cariri Ocidental Paraibano pelo apoio ao desenvolvimento desse trabalho.

\section{REFERÊNCIAS}

Ahid S.M.M., Cavalcante M.D.A., Bezerra A.C.D.S., Soares H.S. \& Pereira R.H.M.A. 2007. Eficácia anti-helmíntica em rebanho caprino no estado de Alagoas, Brasil. Acta Veterinaria Brasilica 1(2):56-59.

Ahmed I., Mehmood S., Munir W., Chaudahry F.R., Miller J.E. \& Qayyum M. 2005. Comparative efficacy of albendazole, levamisole and ivermectin against sheep gastrointestinal nematodes in Pakistan. Proc. $20^{\text {th }}$ International Conference of the World Association for the Advancement of Veterinary Parasitology, Christchurch, p.88.

Blackhall W.J., Pouliot J.F., Prichard R.K. \& Beech R.N. 1998. Haemonchus contortus: selection at a glutamate-gated chloride channel gene in ivermectin and moxidectin selected strains. Exp. Parasitol. 90(1):42-48.

Borges C.C.L. 2003. Atividade in vitro de anti-helmínticos sobre larvas infectantes de nematódeos gastrintestinais de caprinos, utilizando a técnica de coprocultura quantitativa (Ueno, 1995). Parasitologia Latinoamericana 58:142-147, FLAP.

Buzzulini C., Sobrinho A.G.S., Costa A.J., Santos T.R., Borges F.A. \& Soares V.E. 2007. Eficácia anti-helmíntica comparativa da associação albendazole, levamisole e ivermectina à moxidectina em ovinos. Pesq. Agropec. Bras. 42(6):891-895.

Coles G.C., Bauer C., Borgsteede F.H.M., Geerts S., Klei T.R., Taylor M.A. \& Waller P.J. 1992. World Association for the Advancement of Veterinary Parasitology (WAAVP) methods for the detection of anthelmintic resistance in nematodes of veterinary importance. Vet. Parasitol. 44:35-44.

Echevarria F.A.M. \& Trindade G.N.P. 1989. Anthelmintic resistance by Haemonchus contortus to ivermectin in Brazil. Vet. Rec. 124:147148.

Geary T.G. \& Thompson D.P. 2003. Development of antiparasitic drugs in the $21^{\text {st }}$ century. Vet. Parasitol. 115:167-184.

Gordon H.M. \& Whitlock H.V. 1939. A new technique for counting nematode eggs in sheep faeces. Journal Council Science Industry Research of Australia 12:50-52.

Instituto Nacional de Meteorologia. Gráficos. Disponível em: http:// www.inmet.gov.br/html/observacoes.php?lnk=Gráficos. Acesso em 3.9.2009.

Keith R.K. 1953. The differential of the infective larval of some common nematode parasites of cattle. Aust. J. Zool. 2:223-230.

Köhler P. 2001. The biochemical basis of anthelmintic action and resistance. Int. J. Parasitol. 31:336-345.

Lanusse C.E. 1996. Farmacologia dos compostos anti-helmínticos, p.1-44. In: Charles T.P. (Ed.), Controle de Nematóides Gastrintestinais em Ruminantes. Terezinha Padilha, Juiz de Fora.

Le Jambre L.F. \& Whitlock J.H. 1976. Changes in the hatch rate of Haemonchus contortus eggs between geographic regions. Parasitology 73:223-238.

Mattos M.J.T., Oliveira C.M.B., Gouvêa A.S. \& Andrade C.B. 2003. Sensibilidade dos nematódeos gastrintestinais de caprinos ao ivermectin na região da Grande Porto Alegre, RS. Acta Scientiae Veterinariae 31(3):155-160.

Melo A.C.F.L., Reis I.F., Bevilaqua C.M.L., Vieira L.S., Echevarria F.A.M. \& Melo L.M. 2003. Nematódeos resistentes a anti-helmínticos em rebanhos de ovinos e caprinos do estado do Ceará, Brasil. Ciência Rural 33:339-344.

Melo A.C.F.L., Bevilaqua C.M.L. \& Reis I.F. 2009. Resistência aos anti-helmínticos benzimidazóis em nematóides gastrintestinais de pequenos ruminantes do semiárido nordestino brasileiro. Ciênc. Anim. Bras. 10(1):294-300. 
Ministério da Agricultura e Abastecimento 1997. Regulamento Técnico para Licenciamento e/ou Renovação de Licença de Produtos Antiparasitários de Uso Veterinário. Portaria ํㅡ 48, de 12 de maio de 1997. Diário Oficial da União de 16/05/1997, Seção 1, Página 10165.

Molento M.B. 2004. Resistência de helmintos em ovinos e caprinos. XIII Congresso Brasileiro de Parasitologia Veterinária e I Simpósio Latino-Americano de Ricketsioses, Ouro Preto, Minas Gerais. Revta Bras. Parasitol. Vet. 13(1):82-87.

Nascimento S.S. \& Alves J.J.A. 2008. Ecoclimatologia do Cariri Paraibano. Revta Geográfica Acadêmica 2(3):28-41.

Pereira R.H.M.A., Ahid S.M.M., Bezerra A.C.D.S., Soares H.S. \& Fonseca Z.A.A.S. 2008. Diagnóstico da resistência dos nematóides gastrintestinais a anti-helmínticos em rebanhos caprino e ovino do RN. Acta Veterinaria Brasilica 2(1):16-19.

Prichard R. \& Tait A. 2001. The role of molecular biology in veterinary parasitology. Vet. Parasitol. 98:169-194.

Roberts F.H.S. \& O'Sullivan J.P. 1950. Methods for egg counts and larval cultures for strongyles infesting the gastro-intestinal tract of cattle. Aust. J. Agric. Res. 1:99-102.

Rodrigues A.B., Athayde A.C.R., Rodrigues O.G., Silva W.W. \& Faria
E.B. 2007. Sensibilidade dos nematóides gastrintestinais de caprinos a anti-helmínticos na mesorregião do Sertão Paraibano. Pesq. Vet. Bras. 27(4):162-166.

Silvestre A. \& Humbert J.F. 2002. Diversity of benzimidazole-resistance alleles in populations of small ruminant parasites. Int. J. Parasitol. 32:321-328.

Soulsby E.J.L. 1987. Parasitologia y Enfermedades Parasitarias en Ios Animales Domésticos. $7^{\text {th }}$ ed. Nueva Editorial Interamericana, México. 825p.

Valcarcel F., Garcia C.R. \& Romero C. 1999. Prevalence and seasonal pattern caprine trichostrongyles in a dry area central Spain. Zentralbl. Veterinärmed. 46(10):673-681.

Vieira L.S. 1989. Redução do número de ovos por grama de fezes (OPG) em caprinos medicados com anti-helmínticos. Bolm Pesq. 11, Embrapa Caprinos, Sobral. 18p.

Vieira L.S. \& Cavalcante A.C.R. 1999. Resistência anti-helmíntica em rebanhos caprinos no Estado do Ceará. Pesq. Vet. Bras. 19(3/4):99103.

Zar J.H. 1999. Biostatistical Analysis. Prentice Hall, Upper Saddle River, New Jersey. 663p. 